\title{
RETRACTED ARTICLE: Assessment of sustainable exploitable groundwater resources under different water resources management scenarios in the arid salinization region
}

\author{
Shuixian Wang $\cdot$ Bing $\mathrm{Wu} \cdot$ Pengnian Yang
}

Received: 13 August 2013/Accepted: 19 March 2014/Published online: 4 April 2014

(C) Springer-Verlag Berlin Heidelberg 2014

The Editor-in-Chief has decided to retract this article. Upon thorough investigation carried out according to the Committee on Publication Ethics guidelines it has been found that the article duplicates large text blocks, some figures and the general structure and conceptualization of the underlying model from the thesis of Philip Andreas Brunner: Water and salt management in the Yanqi Basin, China. ETH (2005). http://dx.doi.org/10.3929/ethz-a005144054 without proper attribution. The authors have agreed to the retraction.

S. Wang $(\square)$

College of Earth and Environmental Sciences, Lanzhou

University, 222 South Tianshui R, Lanzhou 730000,

People's Republic of China

e-mail: wangshuixian@1zu.edu.cn

B. Wu $\cdot \mathrm{P}$. Yang

College of Water Conservancy and Civil Engineering, Xinjiang

Agriculture University, Urumqi 830052,

People's Republic of China 